\title{
Impact of individual and ecological characteristics on small for gestational age births: an observational study in Quebec
}

\author{
N. Savard, MSc (1, 2); P. Levallois, MD (1, 2, 3); L. P. Rivest, PhD (4); S. Gingras, MSc (2)
}

This article has been peer reviewed.

\begin{abstract}
Introduction: We evaluated associations between ecological variables and the risk of very small for gestational age (VSGA) birth in Quebec in 2000-2008.
\end{abstract}

Methods: Ecological variables came from the Canadian Community Health Survey, the Canadian census and Quebec's birth registry; individual variables also came from Quebec's birth registry. Odds ratios (ORs) adjusted for mother's age, academic qualification, parity, marital status and country of birth were estimated using multilevel logistic regression (generalized estimating equations method).

Results: Births in neighbourhoods with a high proportion of people leading a sedentary lifestyle (OR: 1.07, 95\% confidence interval [CI]: 1.01-1.11) and those with a high/ middle proportion of residents with food insecurity (OR: 1.09, $95 \% \mathrm{CI}$ : 1.05-1.15; OR: 1.05, 95\% CI: 1.01-1.11) had higher odds of VSGA birth. Those with middle proportion of married residents had lower odds of VSGA birth (OR: 0.94, $95 \%$ CI: 0.90-0.98).

Keywords: birth weight, fetal health, reproductive health, social epidemiology, health behaviour, sedentary lifestyle, food insecurity

\section{Introduction}

Individuals with sub-optimal fetal development that results in small for gestational age (SGA) or very small for gestational age (VSGA) birth are at an increased risk of neonatal illness and are more likely to develop type 2 diabetes, hypertension, metabolic syndrome and coronary diseases in adulthood. ${ }^{1}$

Risk factors for sub-optimal fetal development include characteristics of maternal age, race, parity, partnership status, education and smoking. ${ }^{1-3}$ Neighbourhood deprivation is also associated with health ${ }^{4}$ and with a number of modifiable individual risk factors such as smoking and alcohol consumption during pregnancy. ${ }^{5}$
Unfortunately, past ecological analyses were often mostly based on available data rather than on plausible social pathways. ${ }^{4,6}$ In Canada and in the United States, this yielded a set of widely explored neighbourhood census-derived features, including economic deprivation, ${ }^{7-22}$ race, ${ }^{10,11,15,17,19}$ crime, ${ }^{15,23}$ and single-headed households. ${ }^{19}$

A few studies used data from large specific surveys on features of the built and social environment. $8,11,16,24,25$ The researchers observed that social support ${ }^{24}$ and availability or use of neighbourhood services $^{11,16}$ were associated with the risk of adverse birth outcomes, while built environment ${ }^{16}$ and availability of restaurants and supermarkets ${ }^{8}$ were not. Residents' sedentary lifestyles were previously asso- ciated with a higher risk of SGA in a model that was built only from ecological variables for public health purposes. ${ }^{25}$ To our knowledge, residents' food consumption was not included in previous ecological analyses of SGA or VSGA.

We had access to information on singleton births through Quebec's birth registration forms. We collected information about Quebec's local community services centres (CLSC) from three sources: Quebec's birth registration forms, a survey on Canadian residents and the Canadian census. While hypothesizing the model shown in Figure 1 to identify program levers for intervention, we evaluated associations between individual variables and the outcome of VSGA. We also evaluated associations between single and aggregated CLSC territory variables and VSGA.

\section{Methods}

\section{Study population and setting}

The population of this observational study consisted of singleton live births that took place between 2000 and 2008 and their mothers, in Quebec, Canada. Because the survey data from the northern regions of Nord-du-Québec, Terres-Cries-de-la-BaieJames and Nunavik were not methodologically comparable to other provincial regions, we did not include them. Neonates with missing weight or gestational age, those born at less than 22 weeks or more than 43 weeks gestation

\footnotetext{
Author references:

1. Department of Social and Preventive Medicine, Université Laval, Québec, Quebec, Canada

2. Institut national de santé publique du Québec, Québec, Quebec, Canada

3. Centre hospitalier universitaire du Québec, Québec, Quebec, Canada

4. Department of Mathematics and Statistics, Université Laval, Québec, Quebec, Canada

Correspondence: Nathalie Savard, INSPQ, 1000 Route de l'Église, Québec, QC G1V 3V9; Tel.: 418-654-3010 ext. 5741; Fax: 418-654-3032; Email: nathalie.savard.8@ulaval.ca
} 
FIGURE 1

Mother and neonate's individual explanatory variables from the birth registry, Quebec, Canada, 2000-2008

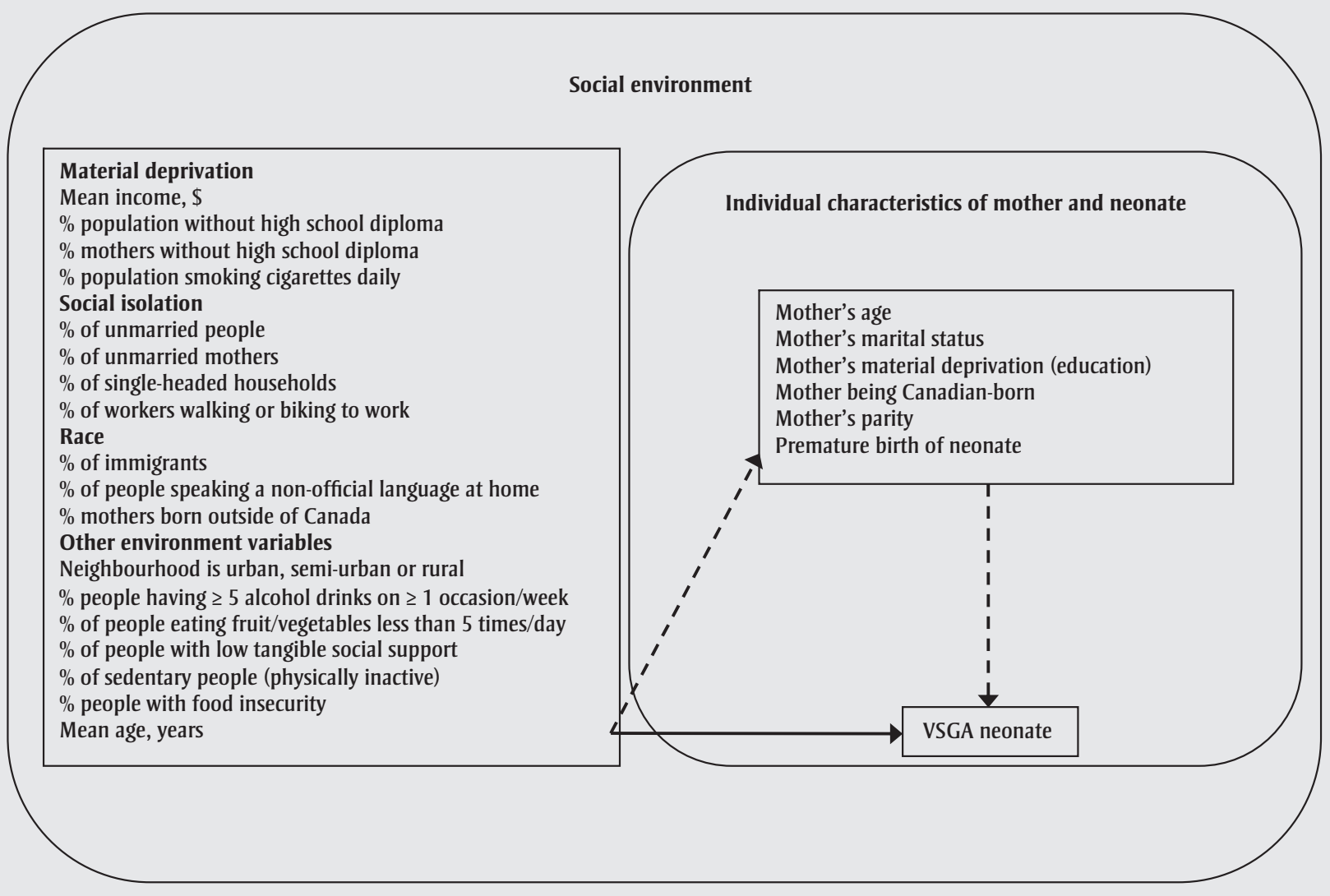

Abbreviation: VSGA, very small for gestational age.

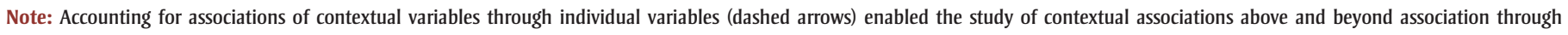
individual variables (full arrow).

and those with implausible weight for gestational age were also excluded. ${ }^{26}$

\section{Territory definition}

Territories were the 143 CLSCs, the first level of organization of the Quebec health care system. CLSCs had an average of 46727 residents and 4666 singleton live births from 2000 to 2008 .

\section{Variables}

\section{Outcome}

Neonates with a weight for gestational age below the $5^{\text {th }}$ percentile on the Canadian sex-specific standardized scale were identified as VSGA. ${ }^{27}$

\section{Individual variables}

We categorized individual characteristics gathered from birth registration forms.
These included maternal age at delivery ( $<20,20-24,25-29,30-34, \geq 35$ years); marital status (married in a civil or religious ceremony vs. unmarried); highest academic qualification (less than high school, high school diploma, college, university and higher); mother's place of birth (Canada vs. not Canada) and parity (primiparous vs. multiparous).

\section{Aggregated ecological variables}

Aggregated ecological variables for births and the whole population of the CLSC (men, other women, youth and the elderly) summarize the average level of a characteristic within the CLSC territory population (Table 1). We calculated birth-oriented variables over CLSC territories by pooling individual data. Population-oriented variables were obtained both by producing proportion-like values from the responses of individuals surveyed in the Canadian
Community Health Survey (CCHS) ${ }^{25,28}$ and by pooling census profiles of sub-territories. The proportions were coded into first, second and third tertiles (for the lowest, middle and upper-most parts of the distribution). The first tertile was the reference for all variables except for mean income, where the third tertile was the reference.

We imputed missing values using the SAS multiple imputation (MI) procedure, with the MCMC method for categorical individual variables and the EM algorithm with the logit transform for proportions. ${ }^{29}$

\section{Data sources}

Birth registration forms from 2000 to 2008 are part of Quebec's registry of demographic events. ${ }^{30}$ The forms include information on all live births (weight at birth, maternal age at delivery, marital status, 
TABLE 1

Explanatory ecological variables at the local community services centre (CLSC) level, Quebec, Canada, 2000-2008

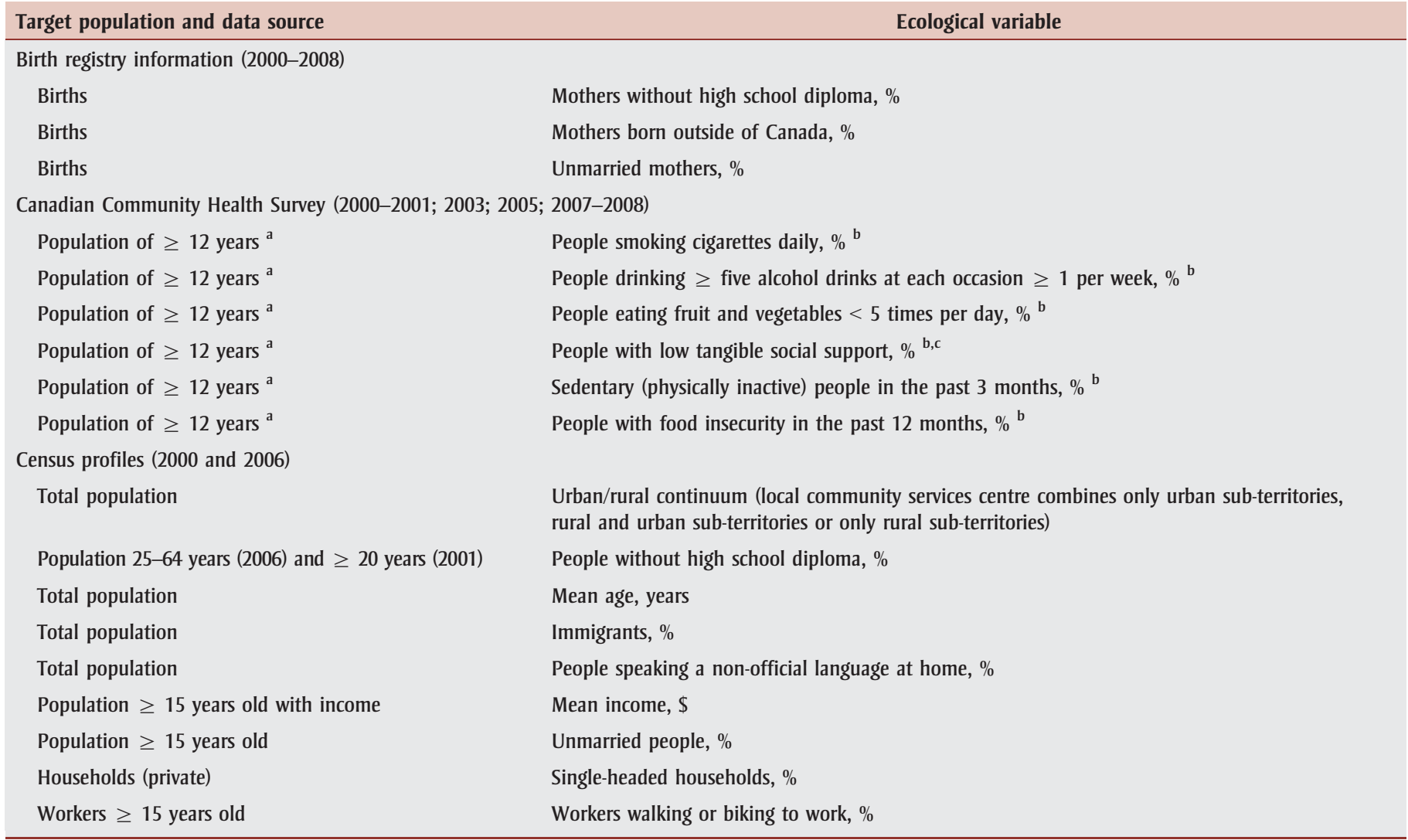

${ }^{a}$ Includes only individuals living at home.

b Proportion-like value that excludes year-cycle and data collection method effects of the survey.

$c<15$ out of 95 on the Social Support Survey subscale of the Medical Outcome Study.

mother's highest academic qualification, mother's place of birth, parity) and the postal code of the mothers' residence at time of giving birth.

The CCHS is a cross-sectional survey that has, to date, been conducted in four yearlong cycles (2000-2001, 2003, 2005 and 2007-2008). ${ }^{28}$ To increase statistical power, we pooled the four survey year-cycles. ${ }^{31}$

The 2001 and 2006 census profiles are available at two sub-territory levels: census tracts and census subdivisions. ${ }^{32}$ Tracts were used in metropolitan areas and subdivisions elsewhere. Hence, sub-territories had similar population sizes. Subterritory profiles were aggregated by CLSC regardless of the year of data collection.

\section{Statistical analysis}

CLSC values were linked to individual births based on the mothers' postal code of residence. Odds ratios (OR) were used to estimate relative risks.

\section{Regression}

We estimated adjusted ORs for individual variables $\left(\mathrm{OR}_{\text {Adjusted }}^{\mathrm{I}}\right)$ using a multilevel logistic regression fitted through generalized estimating equations (GEE). We chose the mother as the first level and the CLSC as the second. ${ }^{33}$ The GEE method provides consistent OR estimates for the population even though the correlation between mothers from the same CLSC is unknown. We assumed this correlation to be small; hence the "independence working correlation" structure was provided as a starting point for the computations. We obtained empirical standard error estimates and thus avoided problems with correlation misspecification. ${ }^{34}$

A deviance test determined whether CLSCs explained a significant part of the unexplained variation resulting from the individual model with interaction terms.

We obtained crude $\mathrm{ORs}\left(\mathrm{OR}^{\mathrm{E}}\right.$ Crude) and ORs adjusted for individual variables and interaction terms $\left(\mathrm{OR}^{\mathrm{E}}\right.$ Adjusted I $)$ using the GEE method for each ecological variable. Interactions between individual variables were selected using the stepwise method with the option "hierarchy = multiple" of the logistic procedure (entry/stay $p$ values $<$.001). A final model was built using variables with significant $\mathrm{OR}^{\mathrm{E}}$ Adjusted I values as candidates in a stepwise method and by forcing inclusion of individual variables as well as interaction terms (entry/ stay $p$ values of .25/.05). GEE parameter estimates adjusted for individual variables and for other ecological variables $\left(\mathrm{OR}^{\mathrm{E}}\right.$ Adjusted IE $)$ were produced for every ecological variable.

Ecological results were restricted to showing those variables with differences in 
crude ORs. We presented a maximum of one material deprivation, racial and social isolation variable (Figure 1) by dataset (all data available from the authors on request).

The adjusted $\mathrm{OR}$ values $\left(\mathrm{OR}^{\mathrm{I}}\right.$ Adjusted, $\mathrm{OR}^{\mathrm{E}}$ Adjusted I and $\mathrm{OR}^{\mathrm{E}}$ Adjusted IE ) were validated by two sensitivity analyses, first, with non-imputed data, and second, by incorporating variables at the smallest possible territory level, that is, census and birth data at the sub-territory level (there are 2368 sub-territories) plus CCHS data at the CLSC level.

The Commission d'accès à l'information du Québec and the Ethics Committee of the Université Laval approved this research project. Analysis was carried out using SAS version 9.2 (MI, LOGISTIC and GENMOD procedures). ${ }^{29}$ Regression results were considered statistically significant if $p$ values were less than .05 .

\section{Results}

\section{Descriptive analysis}

Of the 676165 singleton births recorded in all of Quebec's regions between 2000 and 2008, 7379 were to mothers from northern regions, 850 could not be linked to CLSCs, 67 had no SGA status (missing weight or gestational age), 452 had less than 22 weeks or more than 43 weeks gestation and 163 had implausible weights for gestational age. Thus, our population consisted of a total of 667254 births in 143 CLSCs.

\section{Regression}

Every individual variable was significantly associated with VSGA (Table 2). Mothers without and with a high school diploma and with a college diploma were at a higher risk $\left(\mathrm{OR}_{\text {Adjusted }}^{\mathrm{I}}=2.08,1.53\right.$ and 1.14 , respectfully) of VSGA compared with mothers with a university degree; firsttime mothers were also at a higher risk $\left(\mathrm{OR}_{\text {Adjusted }}^{\mathrm{I}}=1.96\right)$ than other women, all other individual variables being equal.

CLSCs represented a significant part of the unexplained variation that resulted from the individual model with interactions

TABLE 2

Adjusted odds ratios for VSGA singleton live births according to maternal individual explanatory variables, Quebec, Canada, 2000-2008

\begin{tabular}{|c|c|c|c|c|c|}
\hline \multirow[t]{2}{*}{ Variable } & \multirow[t]{2}{*}{$\%$ imputed $^{\text {a }}$} & \multirow[t]{2}{*}{$\mathbf{N}$} & \multirow[t]{2}{*}{$\%$} & \multicolumn{2}{|c|}{ OR $_{\text {Adjusted }}{ }^{b}$} \\
\hline & & & & Estimate & $95 \% \mathrm{Cl}^{\mathrm{c}}$ \\
\hline Age, years & 0.0 & & 100.0 & & $<.001^{\mathrm{d}}$ \\
\hline $20-24$ & & 114780 & 17.2 & 1.00 & $0.96-1.04$ \\
\hline $25-29^{e}$ & & 235120 & 35.2 & 1.00 & - \\
\hline Marital status & 0.0 & & 100.0 & & $<.001^{\mathrm{d}}$ \\
\hline Married $^{\mathrm{e}}$ & & 268130 & 40.2 & 1.00 & - \\
\hline Unmarried & & 399124 & 59.8 & 1.18 & $1.13-1.23$ \\
\hline Highest academic qualification & 8.7 & & 10.1 & & $<.001^{\mathrm{d}}$ \\
\hline$<$ High school & & 67382 & 10.1 & 2.08 & $1.96-2.21$ \\
\hline Mother's country of birth & 1.2 & & 100.0 & & $<.001^{\mathrm{d}}$ \\
\hline Canada $^{\mathrm{e}}$ & & 540272 & 81.0 & 1.00 & - \\
\hline Other & & 126982 & 19.0 & 1.28 & $1.20-1.36$ \\
\hline Parity & 0.0 & & 47.3 & & $<.001^{\mathrm{d}}$ \\
\hline Multiparous $^{\mathrm{d}}$ & & 351539 & 52.7 & 1.00 & - \\
\hline Primiparous & & 315715 & 47.3 & 1.96 & $1.90-2.03$ \\
\hline
\end{tabular}

Abbreviations: $\mathrm{Cl}$, confidence interval; OR, odds ratio; VSGA, very small for gestational age.

a Percentage of births with imputed values.

b Odds ratio adjusted for individual variables (mother's age, mother's marital status, mother's academic degree, mother's country of birth and mother's parity).

c Confidence intervals built using robust variance estimates resulting from a multilevel model fitted using generalized estimating equations (GEE).

${ }^{\mathrm{d}} p$ value of test of global difference.

e Reference category. 
(chi-square statistic $=497.3 p<.001$; $d f=142$ ). For this reason, it was appropriate to include aggregated CLSC variables in the model.

There were significant crude associations between VSGA and every ecological variable presented except for "people eating fruit and vegetables less than five times a day" and "urban/rural continuum" (Table 3; additional data are available from the authors on request). Adjusted ORs $\left(\mathrm{OR}^{\mathrm{E}}\right.$ Adjusted I $)$ were slightly lower than crude values $\left(\mathrm{OR}_{\text {Crude }}^{\mathrm{E}}\right)$, though confidence intervals did not indicate significant differences. When accounting for individual variables, births in CLSCs with lowest mean income $\left(\mathrm{OR}_{\text {Adjusted I }}^{\mathrm{E}}=1.12\right)$ and variables ranking in the third tertile of the following categories had higher risks of VSGA: mothers without high school diploma $\left(\mathrm{OR}^{\mathrm{E}}{ }_{\text {Adjusted I }}=1.12\right)$; immigrants $\left(\mathrm{OR}^{\mathrm{E}}\right.$ Adjusted I $\left.=1.06\right)$; mothers born outside of Canada $\left(\mathrm{OR}^{\mathrm{E}}\right.$ Adjusted I $=$ 1.08); people speaking a non-official language at home $\left(\mathrm{OR}^{\mathrm{E}}\right.$ Adjusted I $\left.=1.08\right)$ and single-headed households $\left(\mathrm{OR}^{\mathrm{E}}{ }_{\text {Adjusted I }}=\right.$ 1.11) (Table 3). Births in CLSCs ranking in second or third tertiles of food insecurity $\left(\mathrm{OR}_{\text {Adjusted I }}^{\mathrm{E}}=1.08 ; 1.14\right)$ and sedentariness $\left(\mathrm{OR}^{\mathrm{E}}\right.$ Adjusted I $\left.=1.06 ; 1.11\right)$ also had higher risks of VSGA, while those in CLSCs ranking in the second tertile with respect to unmarried residents $\left(\mathrm{OR}^{\mathrm{E}}\right.$ Adjusted I $\left.=0.93\right)$ had lower risks.

The final model incorporated ecological variables of food insecurity, sedentariness and partnership status. Births in CLSCs ranking in the second or third tertile of people with food insecurity had higher risks of VSGA (OR $\left.{ }_{\text {Adjusted IE }}^{\mathrm{E}}=1.05 ; 1.09\right)$ when adjusted for all individual variables, unmarried residents and sedentariness. Births in CLSCs ranking in the third tertile of sedentariness also had higher risks of VSGA $\left(\mathrm{OR}_{\text {Adjusted IE }}^{\mathrm{E}}=1.07\right)$ when adjusting for these same variables. In a similar manner, births in CLSCs with middle proportion of unmarried residents had lower risks of VSGA ( $\left.\mathrm{OR}_{\text {Adjusted IE }}^{\mathrm{E}}=0.94\right)$ (Table 3 ).

Adjusted ORs ( $\mathrm{OR}_{\text {Adjusted }}^{\mathrm{I}} \mathrm{OR}^{\mathrm{E}}$ Adjusted I and $\mathrm{OR}^{\mathrm{E}}$ Adjusted IE) would have been similar had we used non-imputed data. Some $\mathrm{OR}_{\text {Adjusted values (for mothers } \geq 35} \geq$ years, for mothers with high school diploma, for those with less than high school, as well as for primiparous mothers) would have been smaller and $\mathrm{OR}^{\mathrm{E}}$ Adjusted I and $\mathrm{OR}^{\mathrm{E}}$ Adjusted IE would have been similar had we studied $5^{\text {th }}$ to $10^{\text {th }}$ percentile of neonatal weights. Likewise, $\mathrm{OR}^{\mathrm{E}}$ Adjusted I and $\mathrm{OR}^{\mathrm{E}}$ Adjusted IE Would have been similar had they been assessed with a logistic model incorporating variables at the smallest possible territory level. Exceptions apply to third tertile mothers without a high school diploma and second tertile single-headed households that had higher $\mathrm{OR}^{\mathrm{E}}$ Adjusted I values in the latter analysis.

\section{Discussion}

We adopted a comprehensive approach to understanding the determinants of fetal health in Quebec, Canada, by using ecological information from a separate survey, birth data and the census in a context in which individual data were available. We found associations between VSGA and ecological variables from each source of data independent of individual variables. Neither census data, survey data nor Quebec's birth data contained such a wide spectrum of relevant area variables. The ecological variables of food insecurity and sedentariness were pertinent for inclusion in a model with several ecological variables. Both were significantly associated with VSGA. Those ecological variables are not necessarily proxies for individual food insecurity and sedentariness. For example, in previous analyses an income below the lowincome cut-off in the CLSC reflected both social isolation and race, whereas mean income reflected material deprivation. ${ }^{25}$

Some of the ecological variables we investigated in this research have also been examined in Canadian and American studies. ${ }^{7,9,13,14,19}$ When individual variables and a few ecological variables were available and accounted for, significant associations were found between SGA and the low-income cut-off both among the births in Quebec from 1991 to $2000^{14}$ and among births in Montréal from 1997 to 2001. 9 There was also a significant association between SGA and material deprivation measured by area income in Ontario from 2004 to $2006 .^{13}$
When individual variables and several ecological variables were accounted for, social isolation and race (measured by single-headed households, low income and ethnicity) were no longer significantly associated with low birth weight among South Carolina births from 2000 to $2003 .{ }^{19}$ These variables were not included in our final model with several ecological variables.

\section{Limitations}

There are a few limitations worth highlighting. First, we were interested in suboptimal fetal development as measured by the VSGA indicator. Some constitutionally small births may not have been a result of sub-optimal fetal development but, being classified as VSGA, contributed to a nondifferential misclassification bias of the outcome. Such misclassification was minimized using the VSGA instead of the SGA indicator.

CLSC exposure was potentially misclassified. By pooling data, we implicitly postulated that CLSC tertiles remained the same throughout the years. Moreover, information about relocated mothers was unavailable. According to 2006 census data, ${ }^{35}$ about $3.5 \%$ of women were incorrectly assigned to the CLSC tertile we had attributed to them. These misclassifications contributed to a small bias toward the null value.

Our results might have been subject to confounding of unmeasured individual factors such as maternal characteristics of social isolation, lifestyle (smoking, caffeine, high alcohol consumption, abuse or sedentariness) and health status (daily caloric intake, maternal body mass index [BMI], maternal hypertension or diabetes in pregnancy).

Our pooled data did not allow us to distinguish the effect of ecological exposure during pregnancy from prior exposure and to note whether the association of deprivation with VSGA has changed over time.

Finally, we were limited by the relatively little knowledge available on the spatial scale that is likely to be relevant to this 
TABLE 3

Crude and adjusted odds ratios for VSGA singleton live births according to ecological variables, Quebec, Canada, 2000-2008

\begin{tabular}{|c|c|c|c|c|c|c|c|c|c|}
\hline \multirow[t]{2}{*}{ Variable $^{\text {a }}$} & \multirow{2}{*}{$\begin{array}{c}\text { Percent } \\
\text { imputed }^{\mathrm{b}} \\
{ }^{\mathrm{b}}\end{array}$} & \multicolumn{2}{|c|}{ Population } & \multicolumn{2}{|c|}{$\mathrm{OR}_{\text {Crude }}^{\mathrm{E}}{ }^{\mathrm{c}}$} & \multicolumn{2}{|c|}{$\mathrm{OR}_{\text {AdjustedI }}^{\mathrm{d}}$} & \multicolumn{2}{|c|}{$\mathrm{OR}_{\text {AdjustedIE }} \mathrm{E}^{\mathrm{E}}$} \\
\hline & & $\mathbf{N}$ & $(\%)$ & Estimate & $95 \% \mathrm{Cl}$ & Estimate & $95 \% \mathrm{Cl}$ & Estimate & $95 \% \mathrm{Cl}$ \\
\hline Mean income, $\$$ & 0.0 & & & & $.001^{f}$ & & $.012^{f}$ & & \\
\hline Highest tertile (28 798-56 036) (reference) & & 331133 & (49.6) & 1.00 & - & 1.00 & - & - & - \\
\hline Middle tertile (25 269-28 797) & & 223233 & (33.5) & 1.07 & $1.00-1.15$ & 1.03 & $0.98-1.09$ & - & - \\
\hline Lowest tertile (16 144-25 268) & & 112888 & (16.9) & 1.22 & $1.13-1.33$ & 1.12 & $1.02-1.15$ & - & - \\
\hline Lowest tertile (1.9-9.3) (reference) & & 309090 & $(41.3)$ & 1.00 & - & 1.00 & - & & \\
\hline Middle tertile (9.3-13.1) & & 229173 & (34.3) & 1.13 & $1.06-1.21$ & 1.05 & $1.00-1.11$ & - & - \\
\hline Highest tertile (13.1-41.6) & & 128991 & (19.3) & 1.25 & $1.15-1.37$ & 1.12 & $1.04-1.20$ & - & - \\
\hline Smoking cigarettes daily, \% & 1.4 & & & & $.04^{\mathrm{f}}$ & & $N S^{f}$ & & \\
\hline Lowest tertile (0.5-20.4) (reference) & & 275503 & $(41.3)$ & 1.00 & - & 1.00 & - & - & - \\
\hline Lowest tertile (0.2-1.3) (reference) & & 106403 & (15.9) & 1.00 & - & 1.00 & - & - & - \\
\hline Middle tertile (1.3-4.8) & & 234675 & (35.2) & 0.96 & $0.89-1.04$ & 0.98 & $0.92-1.05$ & - & - \\
\hline Highest tertile (4.9-61.8) & & 326176 & $(48.9)$ & 1.09 & $1.01-1.17$ & 1.06 & $1.00-1.13$ & - & - \\
\hline Mother born in another country, \% & 0.0 & & & & $.02^{f}$ & & $.03^{f}$ & & \\
\hline Lowest tertile (0.0-1.9) (reference) & & 111383 & $(16.7)$ & 1.00 & - & 1.00 & - & - & - \\
\hline Middle tertile (2.0-8.1) & & 216916 & $(32.5)$ & 1.00 & $0.92-1.09$ & 1.01 & $0.94-1.09$ & - & - \\
\hline Highest tertile (8.2-88.1) & & 338955 & $(50.8)$ & 1.11 & $1.01-1.21$ & 1.08 & $1.00-1.16$ & - & - \\
\hline Unmarried mothers, $\%$ & 0.0 & & & & $.01^{\mathrm{f}}$ & & $N S^{f}$ & & \\
\hline Lowest tertile (14.9-64.9) (reference) & & 315619 & $(47.3)$ & 1.00 & - & 1.00 & - & - & - \\
\hline Walking or biking to work, \% & 0.0 & & & & $.008^{f}$ & & $N S^{f}$ & & \\
\hline Lowest tertile (2.4-6.8) (reference) & & 323121 & $(48.4)$ & 1.00 & - & 1.00 & - & - & - \\
\hline Middle tertile (6.8-10.2) & & 202876 & (30.4) & 1.08 & $1.01-1.15$ & 1.02 & $0.97-1.07$ & - & - \\
\hline Highest tertile (10.3-64.0) & & 141257 & $(21.2)$ & 1.17 & $1.07-1.27$ & 1.08 & $1.01-1.16$ & - & - \\
\hline People with food insecurity, \% & 5.6 & & & & $<.001^{\mathrm{f}}$ & & $<.001^{\mathrm{f}}$ & & $.001^{f}$ \\
\hline Lowest tertile (2.5-10.5) (reference) & & 222636 & (33.4) & 1.00 & - & 1.00 & - & 1.00 & - \\
\hline Middle tertile (10.6-15.1) & & 238685 & (35.8) & 1.13 & $1.05-1.22$ & 1.08 & $1.01-1.15$ & 1.05 & $1.01-1.11$ \\
\hline Highest tertile (15.2-36.4) & & 205933 & (30.9) & 1.25 & $1.16-1.34$ & 1.14 & $1.07-1.21$ & 1.09 & $1.05-1.15$ \\
\hline Sedentariness, \% & 1.4 & & & & $.001^{f}$ & & $.005^{\mathrm{f}}$ & & $.05^{f}$ \\
\hline Lowest tertile (1.7-9.9) (reference) & & 215997 & $(32.4)$ & 1.00 & - & 1.00 & - & 1.00 & - \\
\hline Middle tertile (9.9-14.4) & & 209287 & (31.4) & 1.10 & $1.03-1.18$ & 1.06 & $1.01-1.12$ & 1.03 & $0.98-1.07$ \\
\hline Highest tertile (14.4-75.3) & & 241970 & $(36.3)$ & 1.20 & $1.11-1.29$ & 1.11 & $1.05-1.18$ & 1.07 & $1.01-1.11$ \\
\hline$\geq 5$ alcohol drinks $\geq$ once per week, $\%$ & 2.1 & & & & $.01^{\mathrm{f}}$ & & $N S^{f}$ & & \\
\hline Lowest tertile (0.0-6.9) (reference) & & 256571 & (38.5) & 1.00 & - & 1.00 & - & - & - \\
\hline Middle tertile (6.9-9.7) & & 260022 & $(39.0)$ & 0.91 & $0.85-0.98$ & 0.94 & $0.90-0.99$ & - & - \\
\hline Highest tertile (9.7-20.9) & & 150661 & $(22.6)$ & 1.04 & $0.95-1.13$ & 1.00 & $0.94-1.07$ & - & - \\
\hline
\end{tabular}


TABLE 3 (continued)

Crude and adjusted odds ratios for VSGA singleton live births according to ecological variables, Quebec, Canada, $2000-2008$

\begin{tabular}{|c|c|c|c|c|c|c|c|c|c|}
\hline \multirow[t]{2}{*}{ Variable $^{a}$} & \multirow{2}{*}{$\begin{array}{c}\text { Percent } \\
\text { imputed }^{\mathbf{b}} \\
\%\end{array}$} & \multicolumn{2}{|c|}{ Population } & \multicolumn{2}{|c|}{$O R_{\text {Crude }}{ }^{c}$} & \multicolumn{2}{|c|}{$O R_{\text {AdjustedI }}^{\mathrm{E}}$} & \multicolumn{2}{|c|}{$\mathrm{OR}_{\text {AdjustedIE }}^{\mathrm{E}}$} \\
\hline & & $\mathbf{N}$ & $(\%)$ & Estimate & $95 \% \mathrm{Cl}$ & Estimate & $95 \% \mathrm{Cl}$ & Estimate & $95 \% \mathrm{Cl}$ \\
\hline Mean age, years & 0.0 & & & & $.003^{f}$ & & $.04^{f}$ & & \\
\hline Lowest tertile (25.9-38.3) (reference) & & 264998 & $(39.7)$ & 1.00 & - & 1.00 & - & - & - \\
\hline Middle tertile (38.3-40.5) & & 246054 & (36.9) & 0.99 & $0.91-1.07$ & 0.98 & $0.93-1.04$ & - & - \\
\hline Highest tertile (40.5-51.8) & & 156202 & $(23.4)$ & 1.10 & $1.02-1.20$ & 1.05 & $0.98-1.12$ & - & - \\
\hline
\end{tabular}

Abbreviations: $\mathrm{Cl}$, confidence interval; NS, non significant; OR, odds ratio; VSGA, very small for gestational age.

Note: Confidence interval built using robust variance estimates resulting from a multilevel model fitted through generalized estimating equations.

${ }^{\text {a }}$ The interpretation of an ecological portrait as a proxy of the corresponding individual variable could be inappropriate.

b Percentage of local community services centres with imputed value.

c Crude odds ratio.

' Odds ratio adjusted for individual variables including interaction terms (mother's age, mother's marital status, mother's academic degree, mother's country of birth, mother's parity, academic degree $\times$ marital status, country of birth $\times$ age, country of birth $\times$ marital status, academic degree $\times$ country of birth, age $\times$ parity and academic degree $\times$ parity).

e Odds ratio adjusted for contextual variables (people with food insecurity and inactive people) and for individual variables including interaction terms.

${ }^{f} p$ value for test for global difference.

8 Value $<1.0$.

specific health outcome. ${ }^{36}$ For this reason, sensitivity analyses were done on data pooled by sub-territories.

Mechanisms through which CLSC food insecurity could be associated with lower birth weight for gestational age include interpersonal factors, which have been shown to be consistently related to dietary behaviours in young people. ${ }^{37}$ Higher prepregnancy weight in mothers, an unmeasured factor, could also lead to gestational diabetes. $^{38}$

Residents from CLSCs with less sedentariness or inactivity are certainly globally healthier and have a lower incidence of chronic diseases and disabilities. ${ }^{39}$ Mothers from these CLSCs have a better chance of being physically active themselves. Inactivity of residents might be as a result of the built environment encouraging (or otherwise) activity, ${ }^{37,39,40}$ rather than the social environment doing so. ${ }^{37}$ In addition, activity also reflects the global understanding of public health messages (people eating well, exercising, not smoking, etc.). ${ }^{37}$ Results appear relevant for other countries with similar social welfare systems.

In this effort to enlarge the set of ecological determinants of fetal health, we incorporated data aggregated from a sophisticated Canadian survey with census and birth data to build diversified community-defined portraits. The use of portraits derived from a broad range of variables allowed for the identification of ecological associations between VSGA and marital status, food insecurity and sedentariness of residents. These ecological associations were not identified as "contextual associations" as mothers' food insecurity and sedentariness were not adjusted for in the analyses even though many other individual characteristics were.

Results of this study add to the growing body of evidence suggesting that ecological social processes affect fetal health. Future Canadian studies could benefit from the inclusion of information gathered by large surveys such as the CCHS to the narrow set of census data to depict and use details of neighbourhood contexts in a comprehensive approach.

\section{References}

1. World Health Organization. Promoting optimal fetal development: report of a technical consultation. Geneva $(\mathrm{CH})$ : WHO Press; 2006.
2. Henrichs J, Schenk JJ, Roza SJ, et al. Maternal psychological distress and fetal growth trajectories: the Generation $\mathrm{R}$ Study. Psychol Med. 2010;40:633-43.

3. Blumenshine P, Egerter S, Barclay CJ, Cubbin C, Braveman PA. Socioeconomic disparities in adverse birth outcomes: a systematic review. Am J Prev Med. 2010;39:263-72.

4. Berkman LF, Kawachi I. Social Epidemiology. New York (NY): Oxford University Press; 2000.

5. Timmermans S, Bonsel GJ, SteegersTheunissen RP, et al. Individual accumulation of heterogeneous risks explains perinatal inequalities within deprived neighbourhoods. Eur J Epidemiol. 2010;26:165-80.

6. Riva M, Gauvin L, Barnett TA. Toward the next generation of research into small area effects on health: a synthesis of multilevel investigations published since July 1998. J Epidemiol Community Health. 2007;61: 853-61.

7. Auger N, Giraud J, Daniel M. The joint influence of area income, income inequality, and immigrant density on adverse birth outcomes: a population-based study. BMC Public Health. 2009;9:237. 
8. Farley TA, Mason K, Rice J, Habel JD, Scribner R, Cohen DA. The relationship between the neighbourhood environment and adverse birth outcomes. Paediatr Perinat Epidemiol. 2006;20:188-200.

9. Généreux M, Auger N, Goneau M, Daniel M. Neighbourhood socioeconomic status, maternal education and adverse birth outcomes among mothers living near highways. J Epidemiol Community Health. 2008;62:695-700.

10. Gorman BK. Racial and ethnic variation in low birthweight in the United States: individual and contextual determinants. Health Place. 1999;5:195-207.

11. Jaffee KD, Perloff JD. An ecological analysis of racial differences in low birthweight: implications for maternal and child health social work. Health Soc Work. 2003;28:9-22.

12. Krieger N, Chen JT, Waterman PD, Rehkopf DH, Subramanian SV. Painting a truer picture of US socioeconomic and racial/ ethnic health inequalities: the Public Health Disparities Geocoding Project. Am J Public Health. 2005;95:312-23.

13. Liu N, Wen SW, Katherine W, Bottomley J, Yang Q, Walker MC. Neighbourhood family income and adverse birth outcomes among singleton deliveries. J Obstet Gynaecol Can. 2010;32:1042-8.

14. Luo ZC, Wilkins R, Kramer MS. Effect of neighbourhood income and maternal education on birth outcomes: a populationbased study. CMAJ. 2006;174:1415-20.

15. Masi CM, Hawkley LC, Piotrowski ZH, Pickett KE. Neighborhood economic disadvantage, violent crime, group density, and pregnancy outcomes in a diverse, urban population. Soc Sci Med. 2007;65:2440-57.

16. Muhajarine $\mathrm{N}, \mathrm{Vu}$ LT. Neighbourhood contexts and low birthweight: social disconnection heightens single parents risks in Saskatoon. Can J Public Health. 2009; 100:130-4.

17. Nkansah-Amankra S, Luchok KJ, Hussey JR, Watkins K, Liu X. Effects of maternal stress on low birth weight and preterm birth outcomes across neighborhoods of South Carolina, 2000-2003. Matern Child Health J. 2010;14:215-26.
18. Nkansah-Amankra S, Dhawain A, Hussey JR, Luchok KJ. Maternal social support and neighborhood income inequality as predictors of low birth weight and preterm birth outcome disparities: analysis of South Carolina pregnancy risk assessment and monitoring system survey, 2000-2003. Matern Child Health J. 2010;14:774-85.

19. Nkansah-Amankra S. Neighborhood contextual factors, maternal smoking, and birth outcomes: multilevel analysis of the South Carolina PRAMS survey, 2000-2003. J Womens Health (Larchmt). 2010;19: 1543-52.

20. Pearl M, Braveman P, Abrams B. The relationship of neighborhood socioeconomic characteristics to birthweight among 5 ethnic groups in California. Am J Public Health. 2001;91:1808-14

21. Rich-Edwards JW, Buka SL, Brennan RT, Earls F. Diverging associations of maternal age with low birthweight for black and white mothers. Int J Epidemiol. 2003;32: 83-90.

22. Subramanian SV, Chen JT, Rehkopf DH, Waterman PD, Krieger N. Comparing individual- and area-based socioeconomic measures for the surveillance of health disparities: a multilevel analysis of Massachusetts births, 1989-1991. Am J Epidemiol. 2006;164:823-34.

23. Messer LC, Kaufman JS, Dole N, Herring A, Laraia BA. Violent crime exposure classification and adverse birth outcomes: a geographically-defined cohort study. Int $\mathrm{J}$ Health Geogr. 2006;5:22.

24. Buka SL, Brennan RT, Rich-Edwards JW, Raudenbush SW, Earls F. Neighborhood support and the birth weight of urban infants. Am J Epidemiol. 2003;157:1-8.

25. Savard N, Levallois P, Rivest LP, Gingras S. A study of the association between characteristics of the CLSCs and the risk of small for gestational age births among term and preterm births in Quebec, Canada. Can J Public Health. 2012;103:152-7.

26. Alexander GR, Himes JH, Kaufman RB, et al. A United States national reference for fetal growth. Obstet Gynecol. 1996;87: 163-8.
27. Kramer MS, Platt RW, Wen SW, et al. A new and improved population-based Canadian reference for birth weight for gestational age. Pediatrics. 2001;108(2):E35.

28. Béland Y. Canadian community health survey-methodological overview. Health Rep. 2002;13:9-14.

29. SAS Institute Inc. SAS/STAT 9.2 user's guide: the MI procedure. 2nd ed. Cary (NC): SAS Institute Inc; 2009.

30. Ministère de la Santé et des services sociaux. Registre des événements démographiques Fichier des naissances vivantes (RED/naissances vivantes (K29)) [Internet]. Québec (QC): Government of Quebec; [cited 2011 Feb 10]. Available from: http://www.informa .msss.gouv.qc.ca/Details.aspx? $\mathrm{Id}=\mathrm{pDH} 1 \mathrm{q} 4$ exKSc $=\&$ Source $=/ \mathrm{dlVmYIVYBQ}=$

31. Thomas S, Wannell B. Combining cycles of the Canadian Community Health Survey. Health Rep. 2009;20:53-8.

32. Statistics Canada. Profile for Canada, provinces, territories, census divisions, census subdivisions and dissemination areas, 2006 Census [Internet]. Ottawa (ON): Statistics Canada; [cited 2011 Feb 10]. http://www5 .statcan.gc.ca/bsolc/olc-cel/olc-cel?catno $=94$ $-581-X 2006001 \& l a n g=$ eng

33. Rothman KJ, Greenland S, Lash TL. Modern epidemiology. 3rd ed. Philadelphia (PA): Wolters Kluwer Health/Lippincott Williams \& Wilkins; 2008.

34. Hardin JW, Hilbe JM. Generalized estimating equations. Boca Raton (FL): Chapman \& Hall/CRC; 2002.

35. Statistics Canada. Institut national de santé publique du Québec. Population 5 years and over by mobility status, by province and territory (2006 Census) [Internet]. Ottawa (ON) : Statistics Canada; [cited 2013 July 31]. http://www.statcan.gc.ca /tables-tableaux/sum-som/101/cst01/demo56b -eng.htm

36. Diez Roux AV. Neighborhoods and health: where are we and where do we go from here? Rev Epidemiol Sante Publique. 2007;55:13-21. 
37. De Vet E, de Ridder DT, de Wit JB. Environmental correlates of physical activity and dietary behaviours among young people: a systematic review of reviews. Obes Rev. 2011;12:e130-42.

38. Janevic T, Borrell LN, Savitz DA, Herring AH, Rundle A. Neighbourhood food environment and gestational diabetes in New York City. Paediatr Perinat Epidemiol. 2010;24:249-54.

39. Haskell WL, Blair SN, Hill JO. Physical activity: health outcomes and importance for public health policy. Prev Med. 2009;49:280-2.

40. Durand CP, Andalib M, Dunton GF, Wolch J, Pentz MA. A systematic review of built environment factors related to physical activity and obesity risk: implications for smart growth urban planning. Obes Rev. 2011;12:e173-82. 